\title{
Study of Microstructure and Mechanical Properties of As-built and Heat-treated Additive Manufactured Inconel 718 Alloy
}

\author{
Ajay Kumar Maurya ${ }^{1, *}$ and Amit Kumar ${ }^{1}$ \\ ${ }^{1}$ Department of Mechanical Engineering, National Institute of Technology Patna, Bihar 800005, India \\ *Corresponding author: maurya.me16@nitp.ac.in
}

KEYWORDS
Additive manufacturing
DMLS
Heat treatment
Inconel 718 alloy
Tensile property
SUBMITTED 28 July 2021
REVISED 12 December 2021
ACCEPTED 15 December 2021

\begin{abstract}
Additive manufacturing technology is becoming popular in the industry because it allows the manufacturer to fabricate cost-effective, strong, lightweight, and complex-shaped parts directly from 3D design data as compared with the conventional manufacturing method. Inconel 718 alloy is the most demanding material in aviation as well as in the automobile industry, in terms of manufacturing high-performance parts. In this study, Inconel 718 samples were built using the direct metal laser sintering process, and standard heat treatment was performed on the samples to improve their microstructure and mechanical properties. The as-built samples exhibited good grain structure with fine laves phases, but the matrix was free from $\gamma^{\prime}$ and $\gamma^{\prime \prime}$ phases. During the heat treatment, the strengthening phases $\gamma^{\prime}$ and $\gamma^{\prime \prime}$ precipitated. The mechanical properties of as-built and heat-treated samples were analysed and compared. Tensile tests revealed that the direct-aged sample had the higher tensile strength compared with the other conditions, whereas the as-built samples had higher ductility. Finally, fractography and microstructure analysis were performed to measure the failure modes of tensile specimens.
\end{abstract}

(c) The Author(s) 2021. This article is distributed under a Creative Commons Attribution-ShareAlike 4.0 International license.

\section{INTRODUCTION}

Additive manufacturing (AM) is a layered process in which digital 3D design data is used to fabricate 3D parts by adding layer upon layer. In contrast, subtractive manufacturing involves removing of materials layer by layer to create a finished product. In the AM process, a fine powder or wire-form raw material is used to build the part. This new creation technique permits specialists to plan complex parts that are hard to deliver using traditional strategies (Kranz et al. 2015). This is more practical since there is no material wastage as in regular assembling techniques (Zhang et al. 2013). These unique advantages of AM attract many sectors, medical, automotive, aerospace, and military among them.

Direct metal laser sintering (DMLS) is a 3D manufacturing process used for metal printing that was developed by EOS (Germany). This advanced manufacturing process uses a laser as a power source to fuse and melt the metallic powder to produce a 3D part directly from 3D design data. The layer-based DMLS process has many advantages over traditional manufacturing processes. It produces near-netshape and complex-shaped parts easily, reduces production steps, has zero material wastage, increases flexibility, no tooling is required, and provides high efficiency (Duda and Raghavan 2016). However, parts produced using additive manufacturing techniques have been observed to have high thermal gradients, porosity, and thermal residual stresses. The high thermal gradient and internal thermal stresses are developed in the DMLS-ed part due to the high-power laser used. Rapid cooling of melted layers de- velops directional grain growth in the material structure. Thus, the parts produced by the layered-based technique require post-processing treatment operations to improve their properties (William 2018).

The nickel-based super alloy has been a highdemanding material in industrial applications for over forty years. This super alloy contains $\mathrm{Fe}, \mathrm{Cr}$, and $\mathrm{Nb}$ as its major alloying elements. This alloy has excellent mechanical properties: good compressive stress, high creep resistance, fatigue resistance, high strength, and high corrosion resistance at high temperatures up to $700^{\circ} \mathrm{C}$ (Chlebus et al. 2015; Kranz et al. 2015). Due to these excellent mechanical properties, many components, like jet engine parts, nuclear reactor parts, and gas turbine parts, are made from this alloy. The strengthening of the Inconel 718 alloy is due to the precipitation of $\gamma^{\prime}$ and $\gamma$ " phases available within the FCC $\gamma$ matrix. $\gamma$ ' has a face-centered cubic crystal structure and $\gamma$ " has a bodycentered tetragonal with the composition $\mathrm{Ni}_{3}(\mathrm{Al}, \mathrm{Ti})$ and $\mathrm{Ni}_{3} \mathrm{Nb}$, respectively. Furthermore, many other phases such as $\left(\mathrm{Ni}_{3} \mathrm{Ti}\right), \mathrm{MC}$ carbides $(\mathrm{Nb}, \mathrm{T}) \mathrm{C}$, and laves $(\mathrm{Cr}, \mathrm{Ni}, \mathrm{Fe})_{3}(\mathrm{Ti}$, $\mathrm{Nb}, \mathrm{Mo}$ ) may exist. The $\delta$ phase precipitation present in the metal matrix lowers the strength of the Inconel 718 alloy and the poor diffusibility of $\mathrm{Nb}$, interdendritic segregation of $\mathrm{Nb}$ is very common in conventionally cast or welded IN718 (Huang et al. 1996), and (Rao et al. 2003), which would result in the formation of brittle Laves $(\mathrm{Ni}, \mathrm{Fe}, \mathrm{Cr})_{2}(\mathrm{Nb}, \mathrm{Mo}, \mathrm{Ti})$ phase and deterioration of mechanical properties but the $\delta$ phase is beneficial for controlling grain size at grain boundaries (Farber et al. 2019). 
The mechanical properties of additive printed Inconel 718 parts have been reported in some research papers. Amato et al. (2012) fabricated IN718 samples by the SLM process and observed that grains and columnar micro structures developed in the build direction. The fine columnardendritic micro structure was developed due to the rapid cooling process, but the part produced has a high surface roughness value and high porosity that reduces properties like fatigue. Strano et al. (2013) suggested that as-built samples should be given post-processing treatment to improve their physical and mechanical properties. Strößner et al. (2015) fabricated Inconel samples by a selective laser melting process and studied the micro-structural properties. It was observed that there were differences in the grain sizes for pre- and post-heat-treated samples. They also observed the precipitation behaviour in the samples. Meanwhile, Bean et al. (2018) studied the effects of process parameters on porosity, surface quality, and mechanical properties of Inconel 718 samples. A high yield and ultimate strength was observed, even at higher porosity levels. However, porosity in samples did not meet elongation and area reduction requirements. Smith et al. (2016a) fabricated Inconel 718 samples by 3D printing in the building direction and performed heat treatment. They observed that yield strength varied with testing direction and the hot isostatic pressing (HIP) process lowered yield strength but had higher ductility than annealed and aged samples. Zhao et al. (2008) fabricated Inconel 718 samples by the laser rapid manufacturing (LRM) process and performed mechanical testing. The results obtained were compared between as-built and heat-treated samples. The author revealed that porosity existed in the sample, which was caused by hollow particles available in the gas atomization (GA) powders. Danninger and Weiss (2003) investigated whether porosity and defects are the main causes that affect the mechanical properties of the material and suggested that porosity can be minimised within AM materials by selecting suitable process parameters. Kozior (2020) suggested that to imaging porosity in additive manufacturing, the microCT should be used before and after processing steps. Farber et al. (2019) and Popovich et al. (2017) studied the mechanical properties of Inconel 718 parts after performing the ageing treatment. They subsequently observed that the aforementioned process resulted in better tensile strength in comparison with the as-built samples, but at the same time, the percentage elongation decreases. Wang et al. (2012) observed that the micro structure of the

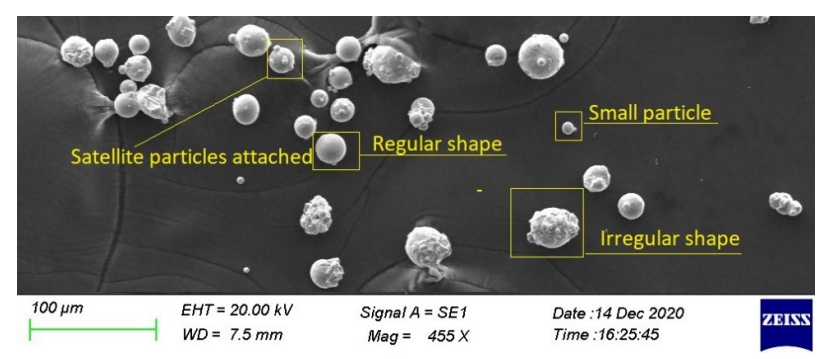

FIGURE 1. Micrograph of as-received IN718 powder.
Inconel 718 alloy was vital for mechanical properties. The author revealed that it was possible to obtain a fine dendritic structure, good metallurgical bonding, and minimal defects using the SLM process. Heat treatment of samples reduced dendritic structure and produced a needle-like $\delta$ phase precipitate at grain boundaries. Cao et al. (2018) fabricated the sample by SLM and performed heat treatment, the $\gamma^{\prime}, \gamma^{\prime \prime}$, and $\delta$ precipitated phases were observed in the heat-treated sample. Zhang et al. (2015) and Lu et al. (2015) studied the mechanical properties of SLM-ed IN718 parts after performing heat treatment and found that the mechanical properties such as hardness and strength of the heat-treated sample increased significantly and were comparable with those of wrought IN718 alloy.

However, there is still a gap observed to study the standard heat treatment effect on the micro structure and mechanical properties of Inconel 718 alloy fabricated by the direct metal laser sintering process. This work mainly focuses on the micro structure and mechanical properties of the Inconel 718 alloy. The experiments were performed and the results obtained were compared and correlated with their micro structures.

\section{MATERIALS AND METHODS}

To conduct the experiments, gas atomized (GA) powder with a nominal particle size of nearly $45 \mu \mathrm{m}$ was used. The raw material (powder) was received from EOS Germany. The weight percent of the chemical elements in the powder is shown in Table 1, and the micrograph of the powder is shown in Figure 1. It was observed that particles of the powder have different shapes and sizes (regular, irregular, small, and large in size). It is thus clear from the micrograph of the powder's particles that the irregular shapes contain pore surfaces.

The samples were fabricated on a DMLS EOS M290 machine (EOS, Germany) and the sample fabrication process are shown in Figure 2. The building chamber was set at an oxygen level of $1.6 \%$ before starting the fabrication process. The Inconel build substrate was preheated to $80^{\circ} \mathrm{C}$ to avoid any distortion in the sample. During fabrication, the building chamber was supplied with Ar gas to avoid any oxidation and contamination inclusion into the part. The bidirectional scanning strategy was applied for this process.

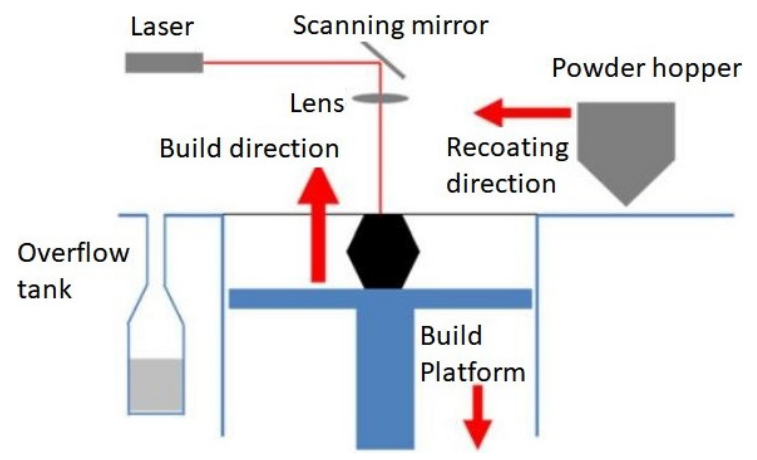

FIGURE 2. DMLS (Sample fabrication process)

TABLE 1. Composition of IN718 powder in \% by weight (min to max).

\begin{tabular}{ccccccccccccccc}
\hline $\mathrm{Ni}$ & $\mathrm{Cr}$ & $\mathrm{Nb}$ & $\mathrm{Mo}$ & $\mathrm{Ti}$ & $\mathrm{Al}$ & $\mathrm{Co}$ & $\mathrm{Cu}$ & $\mathrm{C}$ & $\mathrm{Fe}$ & \\
\hline $50-55$ & $17-21$ & $4.75-5.5$ & $2.8-3.3$ & $0.65-1.15$ & $0.20-0.80$ & $\leq 1$ & $\leq 0.3$ & $\leq 0.08$ & Balance \\
\hline
\end{tabular}


TABLE 2. Process parameters used.

\begin{tabular}{cccc}
\hline Laser power & Layer thickness & Hatch spacing & Scan speed \\
\hline $285 \mathrm{~W}$ & $40 \mu \mathrm{m}$ & $0.11 \mathrm{~mm}$ & $960 \mathrm{~mm} / \mathrm{s}$ \\
\hline
\end{tabular}

The process was as follows: (i) a fine layer of powder, and (ii) a laser beam used to melt the deposited powder layer and to bind the current layer to the previous melted layer. After completing the process, the part was removed from the build chamber. The necessary post-processing techniques were performed to improve the desired mechanical properties. The process parameters used for this study were taken from EOS-listed parameters that are shown in Table 2. The micro-structure, mechanical properties, and residual stress mostly depend on the process parameters and post-processing techniques used by (Lu et al. 2015).

The flat-shaped, miniature-sized tensile sample was designed as per ASTM standard 16a. The samples were fabricated in $0^{0}$ orientation (horizontal direction) only. For this study, all samples were fabricated using the same process parameters. After fabrication, samples were removed from the build chamber and separated from the building substrate with the help of a wire-electro discharge machine. The modelled and fabricated samples are shown in Figure $3 \mathrm{a}$ and 3b, respectively. Per the ASTM standard, the netshape specimen dimensions were $25 \mathrm{~mm}$ in gauge length, $6 \mathrm{~mm}$ in width, and $2.5 \mathrm{~mm}$ in thickness. Of these samples, some were heat-treated at different temperatures.

The as-built part does not exhibit good mechanical and micro-structural properties as it contains non-equilibrium phases and thermal residual stress due to uneven heating and cooling of the layers during the fabrication process. Chlebus et al. (2015) revealed in their study that postprocessed heat treatment generally results in enhanced mechanical properties of SLM-ed parts. Improvements in mechanical properties are essentially required for components that operate under high-stress conditions, such as automotive and aerospace parts. For this purpose, the heat treatment was performed in a closed furnace chamber. These heat treatment processes are homogenised (HSA), solution aged (SA), and direct aged (DA). The heat treatment details are given in Table 3. As-built (AB) means no heat treatment was performed. It may be noted that hot isostatic pressing (HIP) and stress relief methods were not performed in this study.

Tensile testing was performed on the universal testing machine (ZwickRoell Z250, ZwickRoell, Germany) on treated and untreated samples. A uniform strain rate of 1 $\mathrm{mm} / \mathrm{min}$ was maintained for all of the test samples. After performing the test, the fractured surface of the samples was analysed using SEM.

For microstructural testing, sample were mechanically polished from 400 grit to 2500 grit. To reveal different

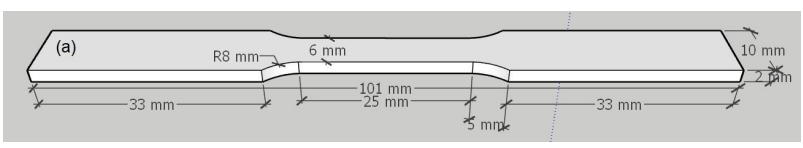

(a)

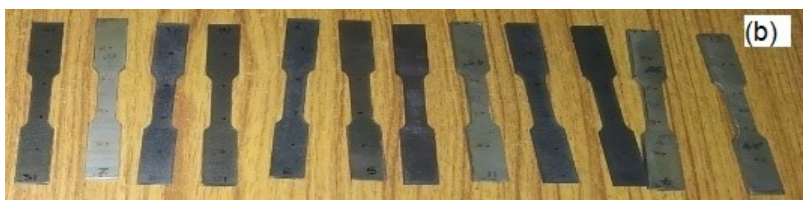

(b)

FIGURE 3. (a) Modelled sample and (b) built sample.

phases, the polished samples were etched for a few seconds using an acid-based solution of $\mathrm{HNO}_{3} 10 \mathrm{ml}$, acetic acid $10 \mathrm{ml}$, and $\mathrm{HCl} 15 \mathrm{ml}$. XRD analysis analysis was also performed.

\section{RESULTS AND DISCUSSION}

\subsection{Mechanical properties of as-built and heat-treated samples}

The tensile test for as-built and heat-treated samples was conducted in an open environment at room temperature. It was observed in Figure 5a, many cracks and holes are present in the samples that reduces the mechanical strength. The small holes may be inherited from the powder material that contains pores (Figure 1). The purpose of applying heat treatments is to homogenize the asmanufactured microstructure and optimize the mechanical properties. Some amount of pores eliminated from the sample after the heat treatment. From Figure 4a, 4b, and 4c, it was observed that heat treatment significantly improved the mechanical properties like ultimate tensile strength, and yield strength as compared to the as-built samples; whereas elongation decreased with heat treatment (Figure $4 \mathrm{~d})$. The lower tensile strength was observed due to the absence of strengthening phases $\gamma$ ' and $\gamma$ " and in the as-built samples. That was further improved by performing the heat treatment that developed strengthening phases like $\gamma$ ' and $\gamma$ ". Performing the heat treatment minimises the pore size and refines the grain of the material. The DA treated samples exhibit higher tensile strength than as-built, SA, and HSA treated samples due to strengthening phases $\gamma$ ' and $\gamma$ ". Heat-treated samples had higher tensile strength than the as-built sample because some strengthening phases was developed in the the samples, also confirmed in XRD analysis. It was observed that the elongation to failure is inversely proportional to the strength for all samples. The lowest strength samples were the as-built samples by performing heat treatment the strength significantly increases by $31.2 \%$ in (DA), and almost same $22.6 \%$ in both the (SA) and (HSA) cases.

TABLE 3. Heat treatment details for IN718 alloy. $F C=$ furnace cooling, $A C=$ air cooling, $H S A=$ homogenization solution aging, $S A=$ solution aging, $A B=$ as-built, and $\mathrm{HT}=$ heat treatment.

\begin{tabular}{|c|c|c|c|c|}
\hline Designation & Short-form & Homogenization $(\mathrm{H})$ & Solution (S) & Ageing $(A)$ \\
\hline As-built & $(A B)$ & None & None & None \\
\hline HSA & $(\mathrm{HT}-1)$ & $1080^{\circ} \mathrm{C} / 1 \mathrm{~h}$ & $960^{\circ} \mathrm{C} / 1 \mathrm{~h}$ & $720^{\circ} \mathrm{C} / 8 \mathrm{~h} / \mathrm{FC}$ at $50^{\circ} \mathrm{C} / \mathrm{h}$ to $620^{\circ} \mathrm{C} / 8 \mathrm{~h} / \mathrm{AC}$ \\
\hline SA & (HT-2) & None & $960^{\circ} \mathrm{C} / 1 \mathrm{~h}$ & $720^{\circ} \mathrm{C} / 8 \mathrm{~h} / \mathrm{FC}$ at $50^{\circ} \mathrm{C} / \mathrm{h}$ to $620^{\circ} \mathrm{C} / 8 \mathrm{~h} / \mathrm{AC}$ \\
\hline Direct ageing (DA) & $(\mathrm{HT}-3)$ & None & None & $720^{\circ} \mathrm{C} / 8 \mathrm{~h} / \mathrm{FC}$ at $50^{\circ} \mathrm{C} / \mathrm{h}$ to $620^{\circ} \mathrm{C} / 8 \mathrm{~h} / \mathrm{AC}$ \\
\hline
\end{tabular}




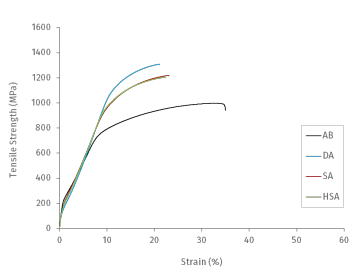

(a)

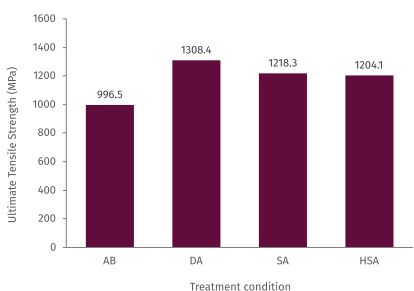

(b)

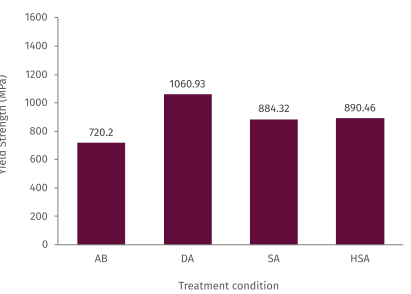

(c)

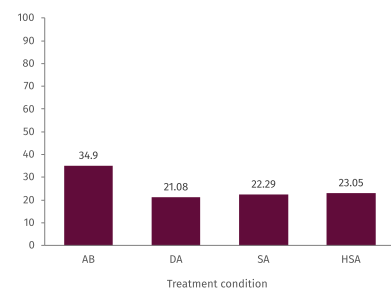

(d)

FIGURE 4. (a) Tensile curve, (b) ultimate tensile strength, (c) yield strength, and (d) strain.

\subsection{Fracture behaviour of as-built and heat-treated samples}

The effect of heat treatment on fracture behaviour and tensile properties were examined. The cracks propagate in the mixed intergranular and intragranular mode for both as-built (Figure 5a) and heat-treated samples (Figure 5b, 5c, $5 \mathrm{~d})$, which confirms inter-granular and intragranular grain facets. The fractured surface of as-built was consisting of uniformly distributed dimples and tear ridges. Most of the dimples were bigger than $1 \mu \mathrm{m}$. Similarly, dimples and tear ridges on the fractured of the HTed were homogeneous. However, the dimples on the HTed fracture surface were smaller and shallower. It was observed on the fractured surface that small dimples present on the fractured surface confirmed that the fracture occurred in a ductile manner. The fracture occurred in the as-built sample due to the inclusion of particles (inherited from the raw powder). Thus, the as-built sample reports higher elongation than heattreated samples, and after applying the heat treatment to samples, the alignment of dimples seems to vanish in the case of DA, SA, and HSA. The fractured surfaces look relatively similar in pattern, as indicated in Figure 5b, 5c, and 5d. According to Lu et al. (2015), the size and depth of dimples are indications of ductility and elongation.

\subsection{Effect of heat treatment on micro-structure and mechanical properties}

The heat treatment was performed to homogenize the structure and to improve the desired mechanical properties of the as-built samples. The precipitation of laves and the segregation of $\mathrm{Nb}$ are minimised because of the cooling effect, which is typically higher in the DMLS process during solidification as compared to the casting process. Therefore, $\mathrm{Nb}$ forms present in the $\gamma$ matrix may be observed in the as-built sample Antonsson and Fredriksson (2005). Inconel 718 is a precipitation hardening alloy with the BCT, $\gamma$ " $\left(\mathrm{Ni}_{3} \mathrm{Nb}\right)$ being the main strengthening phase that forms a coherent precipitate with the parent $\gamma$ (FCC) matrix phase. The standard heat treatment specified by AMS5664, which

is solutionizing at $960^{\circ} \mathrm{C}$, furnace cooling followed by twostage ageing treatment at $720^{\circ} \mathrm{C} / 8 \mathrm{~h}$ and $620^{\circ} \mathrm{C} / 8 \mathrm{~h}$, is given in Table 3 . The resulting microstructure has a fine nano-sized " that has higher tensile strength than the original. Applying direct ageing treatment, the strengthening phase $\gamma^{\prime \prime}$ precipitate appears from the Nb in $\gamma$ matrix. However, the $\mathrm{Nb}$ form available in the $\gamma$ matrix is dependent on the heat treatment process like SA/HSA, which may either precipitate the $\mathrm{Nb}$-consuming $\delta$ phase or dissolve the $\mathrm{Nb}$ consuming laves phase. But at a low temperature, no $\mathrm{Nb}$ form was released from Laves in direct ageing treatment (Figure 6d). At higher temperatures, say $960^{\circ} \mathrm{C}(\mathrm{SA}), \mathrm{Nb}$ was partially extracted from and dissolved in some laves phases, and the $\delta$ phase was then precipitated by consuming $\mathrm{Nb}$ (Figure 6e). The dissolution of Laves is beneficial to release more $\mathrm{Nb}$ and $\mathrm{Ti}$ elements to form the strengthening phases during the subsequent aging treatment. The $\delta$ phases have not been observed in the HSA specimen owing to a homogenization temperature above the $\delta$-solvus line temperature of $1100^{\circ} \mathrm{C}$ (Azadian et al. 2004).

As a result, the $\mathrm{Nb}$ available for precipitating $\gamma$ " is expected to be lower than in DA conditions. At a higher temperature, say $1080^{\circ} \mathrm{C}$ (homogenization case), homogeneously reduces the $\mathrm{Nb}$ in $\gamma$ matrix by completely dissolving all the Laves phase. As shown in Figure $6 \mathrm{c}$, less $\mathrm{Nb}$ is available for "precipitating" in HSA than in DA and SA treatments. Some of the Nb is expended in HSA treatment to precipitate the $\delta$ phase at grain boundaries. However, no significant change in the tensile strength occurs in SA and HSA due to precipitation of $\gamma$ ", which was measured experimentally and compared in Figure 4.

The changes observed in mechanical properties at different conditions were calculated and compared in Table

TABLE 4. Yield strength ratio compared between as-built and heattreated conditions.

\begin{tabular}{ccccc}
\hline Treatment conditions & AB & DA (HT-3) & SA (HT-2) & HSA (HT-1) \\
\hline$\frac{œ(\mathrm{AB} \text { or } \mathrm{HT})}{œ(\mathrm{AB})}$ & 1 & 1.473 & 1.227 & 1.236 \\
\hline
\end{tabular}

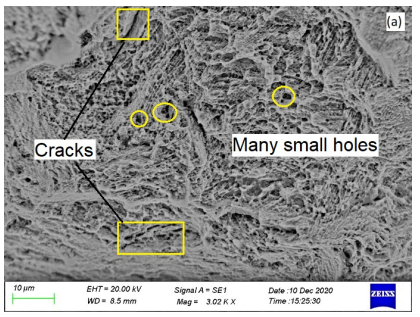

(a)

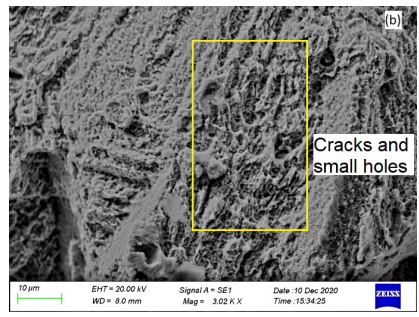

(b)

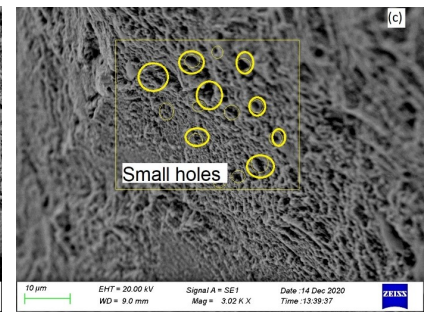

(c)

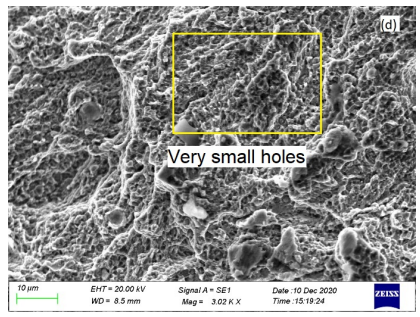

(d)

FIGURE 5. Fractured surfaces of (a) as-built (AB), (b) direct ageing (DA), (c) solution ageing (SA), (d) homogenization solution ageing (HSA). 


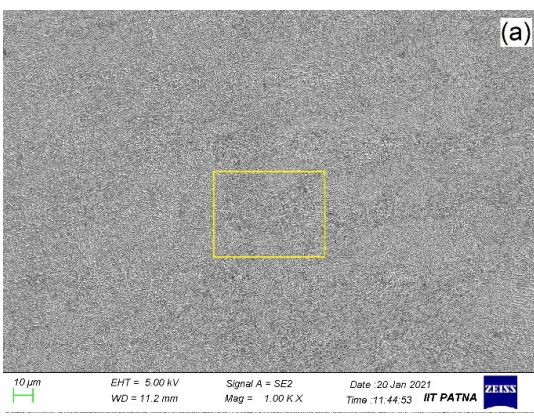

(a)

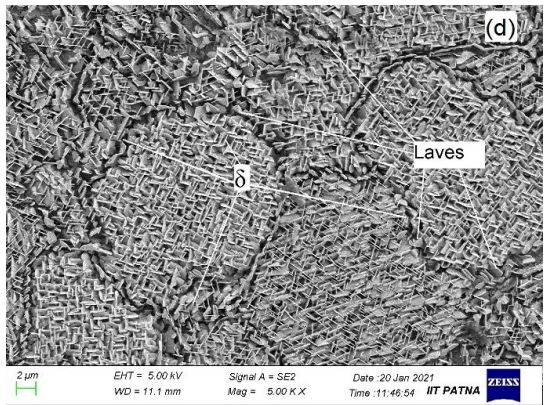

(d)

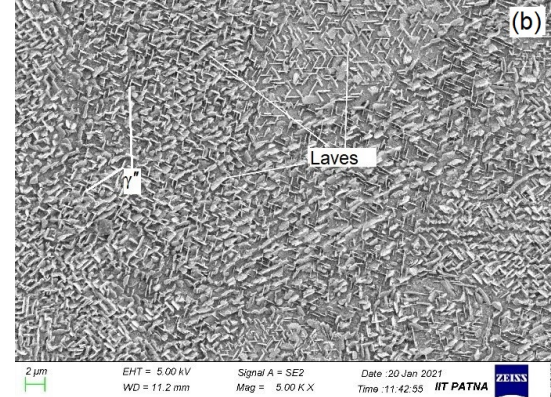

(b)

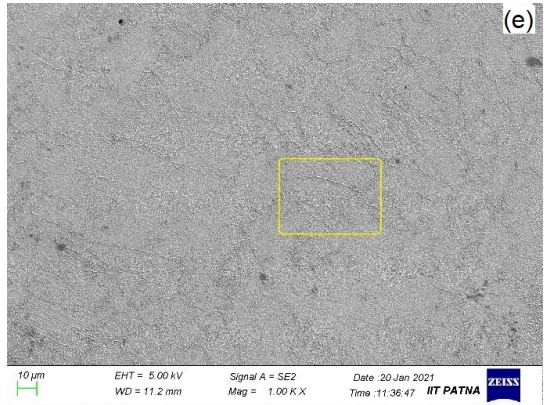

(e)

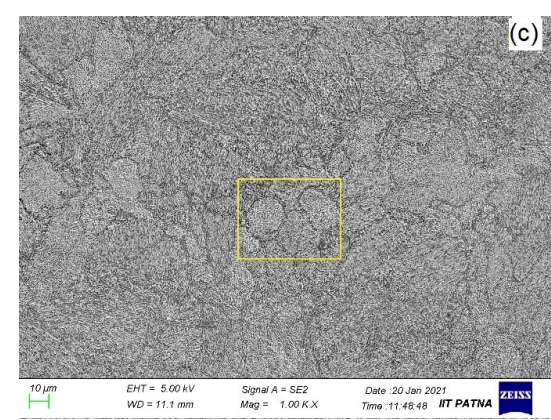

(c)

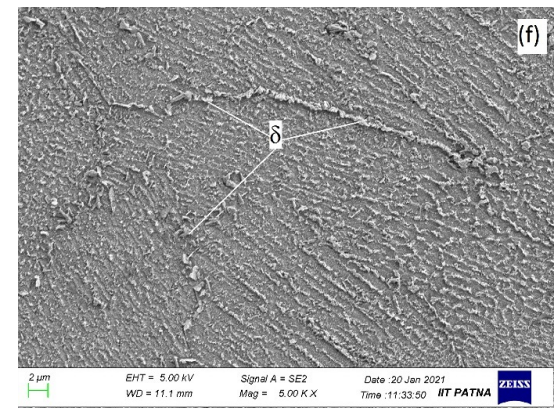

(f)

FIGURE 6. Microstructure of (a) DA, (c) SA, and (e) HSA samples, and magnified regions of a, c, and e are b, d, and f, respective1y.

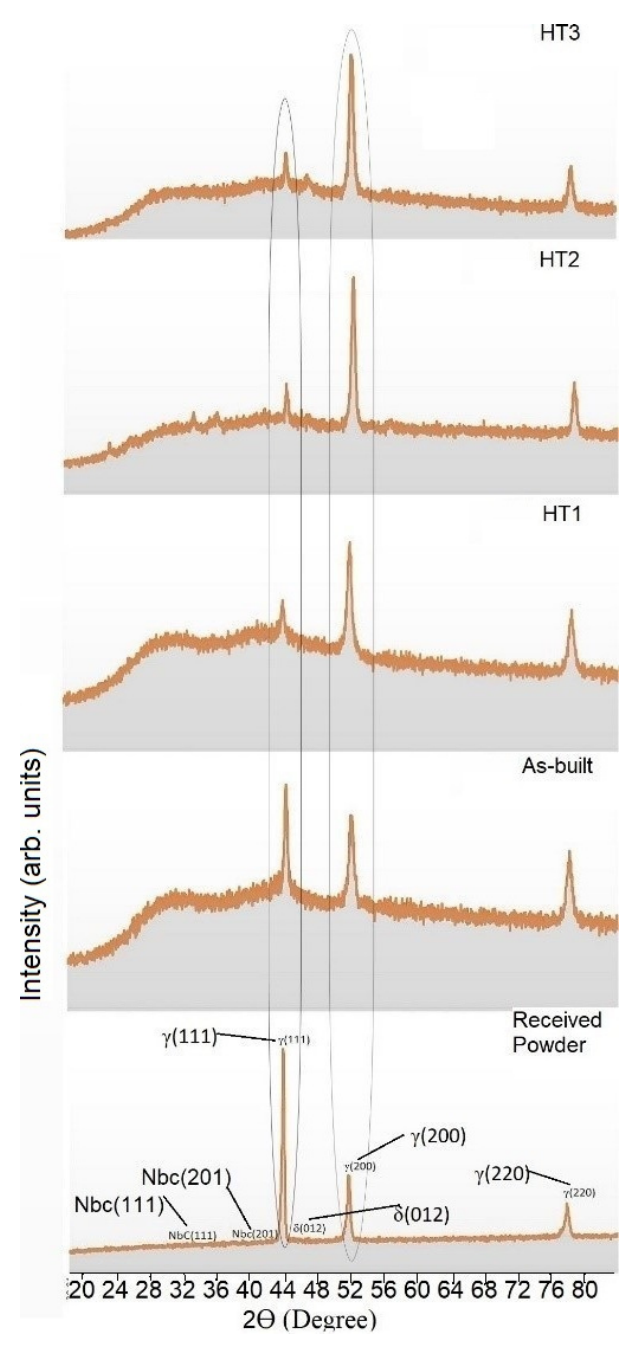

FIGURE 7. XRD of as-built and heat-treated samples

4. It was clear from Table 4 that the heat treatment significantly improved the properties like yield strength and ulti- mate tensile strength but decreased the ductility. The DA sample exhibits higher yield strength than the SA and HSA samples. The SA and HSA treatments partially changed the microstructures, reduced the amount of porosity, and removed the residual stress that was developed in an as-built sample during fabrication.

\subsection{XRD analysis}

The XRD analysis was conducted for treated and untreated samples as shown in Figure 7. The peak was mainly attributed to the $\gamma$-matrix of the deposits. It is difficult to confirm the precipitation of the strengthening phase $\gamma$ " \& $\gamma$ ' using XRD without prolonged annealing or coarsening of the precipitates. The strengthening phases such as $\gamma$ ' and $\gamma$ " dissolved in the $\gamma$-matrix that was partially formed and precipitated during deposition. It was observed lower peak intensity of $\gamma(111)$ than $\gamma(200)$ in DA samples compared to the as-built, SA, and HSA samples.

It is generally observed that heat treatment changes the peak positions and peak intensities that confirm microstructural changes in texture and secondary phase precipitation. The lower peak intensity of $\gamma(111)$ observed than of $\gamma(200)$ suggests performing homogenization (HT1) treatment for $1 \mathrm{~h}$ was not enough to modify the texture along $\gamma(200)$ of the as-built sample as shown in Figure 7 . The changes in peak positions confirmed the precipitation or/and dissolution of $\mathrm{Mo}, \mathrm{Ti}$, and $\mathrm{Nb}$ during the heat treatments (Smith et al. 2016b). After ageing treatment, $\gamma(111)$ of the $\gamma$-matrix shifted to higher diffraction angles due to the precipitation of the strengthening phases, $\gamma^{\prime \prime}\left(\mathrm{Ni}_{3} \mathrm{Nb}\right)$, and $\gamma^{\prime}\left(\mathrm{Ni}_{3}(\mathrm{Ti}, \mathrm{Al})\right)$ that consumed $\mathrm{Nb}$ and $\mathrm{Ti}$ from the matrix. The distribution of precipitates such as $\gamma^{\prime}, \gamma^{\prime \prime}$ and $\delta$ revealed the strengthening phase.

\section{CONCLUSIONS}

The present study focused on the microstructure and mechanical properties of treated and untreated samples of 
the IN718 alloy. The results obtained are given as follows. After applying heat treatment, the tensile properties significantly improved as compared to the as-built samples. Higher strength was observed for direct ageing (DA) conditions.

The as-built samples exhibit good grain structure with fine laves phases, but the matrix is free from $\gamma^{\prime}$ and $\gamma$ " phases. Performing the heat treatment, the strengthening phases $\gamma$ ' and $\gamma$ " precipitated. Some of these precipitates are consumed in the laves phase before precipitating in the $\delta$ phase. The higher ductility was observed for as-built samples as compared to heat-treated samples. Higher yield and tensile strengths were observed in direct-aged treated samples.

\section{ACKNOWLEDGMENTS}

Thanks to CTRTC Bhubaneswar, India for help with sample fabrication. Thanks to the department of mechanical engineering NIT Patna for providing lab facilities, thanks to Aryabatta knowledge university for providing fractography test, and IIT Patna for conducting microstructure test. The work was financially supported by the ministry of education GOI.

\section{AUTHORS' CONTRIBUTIONS}

AKM conceived the ideas, fabricated the samples, performed the experiments, interpreted the data, and wrote and edited the manuscript. AK led the proofreading, commenting, and editing of the manuscript. All authors contributed critically to the drafts and gave final approval for publication.

\section{COMPETING INTERESTS}

The authors declare no competing interest

\section{REFERENCES}

Amato KN, Gaytan SM, Murr LE, Martinez E, Shindo PW, Hernandez J, Collins S, Medina F. 2012. Microstructures and mechanical behavior of Inconel 718 fabricated by selective laser melting. Acta Materialia. 60(5):22292239. doi:10.1016/j.actamat.2011.12.032.

Antonsson T, Fredriksson H. 2005. The effect of cooling rate on the solidification of INCONEL 718. Metall Mater Trans B. 36(1):85-96. doi:10.1007/s11663-005-0009-0.

Azadian S, Wei LY, Warren R. 2004. Delta phase precipitation in inconel 718. Mater Charact. 53(1):7-16. doi: 10.1016/j.matchar.2004.07.004.

Bean GE, Witkin DB, McLouth TD, Patel DN, Zaldivar RJ. 2018. Effect of laser focus shift on surface quality and density of Inconel 718 parts produced via selective laser melting. Addit Manuf. 22:207-215. doi:10.1016/j.addma. 2018.04.024.

Cao GH, Sun TY, Wang CH, Li X, Liu M, Zhang ZX, Hu PF, Russell AM, Schneider R, Gerthsen D, Zhou ZJ, Li CP, Chen GF. 2018. Investigations of $\gamma^{\prime} \gamma^{\prime \prime}$ and $\delta$ precipitates in heat-treated Inconel 718 alloy fabricated by selective laser melting. Mater Charact. 136:398-406. doi:10.101 6/j.matchar.2018.01.006.

Chlebus E, Gruber K, Kuźnicka B, Kurzac J, Kurzynowski T. 2015. Effect of heat treatment on the microstructure and mechanical properties of Inconel 718 processed by selective laser melting. Mater Sci Eng A. 639:647-655. doi:10.1016/j.msea.2015.05.035.

Danninger H, Weiss B. 2003. The influence of defects on high cycle fatigue of metallic materials. J Mater Process Technol. 143-144(1):179-184. doi:10.1016/S0924-0136 (03)00409-6.

Duda T, Raghavan LV. 2016. 3D metal printing technology. IFAC-PapersOnLine. 49(29):103-110. doi:10.1016/j.ifac ol.2016.11.111.

Farber B, Small KA, Allen C, Causton RJ, Nichols A, Simbolick J, Taheri ML. 2019. Corrigendum to "Correlation of mechanical properties to microstructure in Metal Laser Sintering Inconel 718" [Mater. Sci. Eng. A 712 (2018) 539547]. Mater Sci Eng A. 743:636. doi:10.1016/j.msea.2018. 01.071.

Huang X, Chaturvedi MC, Richards NL. 1996. Effect of homogenization heat treatment on the microstructure and heat-affected zone microfissuring in welded cast alloy 718. Metall Mater Trans A. 27(3):785-790. doi: 10.1007/BF02648966.

Kozior T. 2020. The influence of selected selective laser sintering technology process parameters on stress relaxation, mass of models, and their surface texture quality. 3D Print Addit Manuf. 7(3):126-138. doi:10.1089/3dp.20 19.0036.

Kranz J, Herzog D, Emmelmann C. 2015. Design guidelines for laser additive manufacturing of lightweight structures in TiAl6V4. J Laser Appl. 27(S1):S14001. doi: 10.2351/1.4885235.

Lu Y, Wu S, Gan Y, Huang T, Yang C, Junjie L, Lin J. 2015. Study on the microstructure, mechanical property and residual stress of SLM Inconel-718 alloy manufactured by differing island scanning strategy. Optics Laser Technol. 75:197-206. doi:10.1016/j.optlastec.2015.07. 009.

Popovich VA, Borisov EV, Popovich AA, Sufiiarov VS, Masaylo DV, Alzina L. 2017. Impact of heat treatment on mechanical behaviour of Inconel 718 processed with tailored microstructure by selective laser melting. Mater Des. 131:12-22. doi:10.1016/j.matdes.2017.05.065.

Rao GA, Kumar M, Srinivas M, Sarma DS. 2003. Effect of standard heat treatment on the microstructure and mechanical properties of hot isostatically pressed superalloy inconel 718. Mater Sci Eng A. 355(1-2):114-125. doi:10.1016/S0921-5093(03)00079-0.

Smith DH, Bicknell J, Jorgensen L, Patterson BM, Cordes NL, Tsukrov I, Knezevic M. 2016a. Microstructure and mechanical behavior of direct metal laser sintered Inconel alloy 718. Mater Charact. 113:1-9. doi:10.1016/j.matchar. 2016.01.003.

Smith RJ, Hirsch M, Patel R, Li W, Clare AT, Sharples SD. 2016b. Spatially resolved acoustic spectroscopy for selective laser melting. J Mater Process Technol. 236:93102. doi:10.1016/j.jmatprotec.2016.05.005.

Strano G, Hao L, Everson RM, Evans KE. 2013. Surface roughness analysis, modelling and prediction in selective laser melting. J Mater Process Technol. 213(4):589597. doi:10.1016/j.jmatprotec.2012.11.011.

Strößner J, Terock M, Glatzel U. 2015. Mechanical and microstructural investigation of nickel-based superalloy IN718 manufactured by selective laser melting (SLM). Adv Eng Mater. 17(8):1099-1105. doi:10.1002/adem.2 01500158.

Wang Z, Guan K, Gao M, Li X, Chen X, Zeng X. 2012. The microstructure and mechanical properties of deposited- 
IN718 by selective laser melting. J Alloys Compd. 513:518-523. doi:10.1016/j.jallcom.2011.10.107.

William EF. 2018. Metal additive manufacturing-a review. In: Materials selection and design. ASM International. p. 1-9. doi:10.31399/asm.hb.v20.a0009211.

Zhang B, Dembinski L, Coddet C. 2013. The study of the laser parameters and environment variables effect on mechanical properties of high compact parts elaborated by selective laser melting 316L powder. Mater Sci Eng A. 584:21-31. doi:10.1016/j.msea.2013.06.055.
Zhang D, Niu W, Cao X, Liu Z. 2015. Effect of standard heat treatment on the microstructure and mechanical properties of selective laser melting manufactured Inconel 718 superalloy. Mater Sci Eng A. 644:32-40. doi:10.1016/j.msea.2015.06.021.

Zhao X, Chen J, Lin X, Huang W. 2008. Study on microstructure and mechanical properties of laser rapid forming Inconel 718. Mater Sci Eng A. 478(1-2):119-124. doi: 10.1016/j.msea.2007.05.079. 